This item was submitted to Loughborough's Research Repository by the author.

Items in Figshare are protected by copyright, with all rights reserved, unless otherwise indicated.

\title{
Objective physical activity and physical performance in middle-aged and older adults
}

PLEASE CITE THE PUBLISHED VERSION

https://doi.org/10.1016/j.exger.2019.02.003

PUBLISHER

(C) Elsevier

VERSION

AM (Accepted Manuscript)

PUBLISHER STATEMENT

This paper was accepted for publication in the journal Experimental Gerontology and the definitive published version is available at https://doi.org/10.1016/j.exger.2019.02.003

LICENCE

CC BY-NC-ND 4.0

\section{REPOSITORY RECORD}

Spartano, Nicole L., Asya Lyass, Martin G. Larson, Tuyen Tran, Charlotte Andersson, Susan J. Blease, Dale Esliger, Ramachandran S. Vasan, and Joanne M. Murabito. 2019. "Objective Physical Activity and Physical Performance in Middle-aged and Older Adults". figshare. https://hdl.handle.net/2134/37619. 


\section{Accepted Manuscript}

Objective physical activity and physical performance in middleaged and older adults

Nicole L. Spartano, Asya Lyass, Martin G. Larson, Tuyen Tran, Charlotte Andersson, Susan J. Blease, Dale W. Esliger, Ramachandran S. Vasan, Joanne M. Murabito

PII: S0531-5565(18)30511-4

DOI: https://doi.org/10.1016/j.exger.2019.02.003

Reference: EXG 10563

To appear in: Experimental Gerontology

Received date: 14 August 2018

Revised date: 4 December 2018

Accepted date: 4 February 2019

Please cite this article as: N.L. Spartano, A. Lyass, M.G. Larson, et al., Objective physical activity and physical performance in middle-aged and older adults, Experimental Gerontology, https://doi.org/10.1016/j.exger.2019.02.003

This is a PDF file of an unedited manuscript that has been accepted for publication. As a service to our customers we are providing this early version of the manuscript. The manuscript will undergo copyediting, typesetting, and review of the resulting proof before it is published in its final form. Please note that during the production process errors may be discovered which could affect the content, and all legal disclaimers that apply to the journal pertain. 


\section{Objective physical activity and physical performance in middle-aged and older adults}

Nicole L. Spartano, ${ }^{1,2}$ Asya Lyass, ${ }^{2,3}$ Martin G. Larson, ${ }^{2,4}$ Tuyen Tran, ${ }^{4}$ Charlotte Andersson, ${ }^{2,5}$ Susan J. Blease, ${ }^{2}$ Dale W. Esliger, ${ }^{6}$ Ramachandran S. Vasan, ${ }^{2,7}$ Joanne M. Murabito ${ }^{2,8}$

1. Section of Endocrinology, Diabetes, Nutrition, and Weight Management, Boston University School of Medicine, Boston, MA, USA.

2. Framingham Heart Study, Framingham, MA, USA.

3. Department of Mathematics and Statistics, Boston University, Boston, MA, USA.

4. Department of Biostatistics, Boston University, Boston, MA, USA.

5. Department of Cardiology, Herlev and Gentofte Hospital, Gentofte, Denmark.

6. School of Sport, Exercise and Health Sciences, Loughborough University, Loughborough, UK.

7. Sections of Preventive Medicine and Epidemiology, and Cardiovascular Medicine, Department of Medicine, Boston University School of Medicine, Boston, MA, USA.

8. Department of General Internal Medicine, Boston University School of Medicine, Boston, MA, USA.

Short title: Physical activity and physical performance

\section{Corresponding Author}

Nicole Spartano, $\mathrm{PhD}$

Boston University School of Medicine

Section of Endocrinology, Diabetes, Nutrition \& Weight Management

720 Harrison Avenue, Doctors Office Building, Suite 8100

Boston, MA 02118

Phone: 315-415-2040

Email: Spartano@bu.edu

Title characters: 84

Abstract word count: 249

Total manuscript word count: 3417

Tables: 3

Figures: 2

Supplemental Tables: 2

Supplemental Figures: 1

References: 48

Funding: This work was supported by the National Institutes of Health grants (NHLBI-N01HC25195, HHSN268201500001I; R01-AG047645; R01-HL131029; R56-AG029451); the American Heart Association (15GPSGC24800006 and 16MCPRP30310001). Dr. Vasan is supported in part by the Evans Medical foundation and the Jay and Louis Coffman Endowment, Department of Medicine, BUSM. 


\begin{abstract}
Background: Older adults may have difficulty meeting the Physical Activity (PA) Guidelines. A favorable balance between PA and sedentary time (SED) is an important determinant of physical performance in older adults. Our objective was to explore associations of PA/SED with physical performance across mid-older age in adults without overt mobility disability.

Methods: Framingham Offspring Study participants free of mobility disability with accelerometry and physical performance data (gait speed, chair stand time, and handgrip strength), were studied in cross-sectional analysis $(n=1352)$. We regressed physical performance on PA level, measured using steps, moderate to vigorous (MV)PA and SED. We stratified by age groups, adjusted for covariates, and modelled MVPA and SED separately and together as predictors.
\end{abstract}

Results: Only $38 \%$ of adults $50-64$ years and $15 \%$ of adults $\geq 75$ years met the PA Guidelines (i.e., 150 minutes MVPA per week). Individuals achieving at least 5 minutes/day of MVPA had $0.062 \pm 0.013 \mathrm{~m} / \mathrm{s}$ greater gait speed and better chair stands and handgrip strength (in women) than those with $<5$ minutes/day of MVPA $(\mathrm{p}<0.01)$ across mid-older age. SED was associated with poorer performance on gait speed and chair stand tests, but results were not significant after adjusting for MVPA ( $>>0.05$ ). For adults $\geq 75$ years, every 5000 more steps/day related to $\sim 0.045$ $\mathrm{m} / \mathrm{s}$ greater gait speed $(\mathrm{p}=0.006)$.

Conclusion: Our cross-sectional study demonstrated that, across mid-older adulthood, MVPA related to better physical performance, but in adults $\geq 75$ years, total steps walked associated with better gait speed. These data warrant future research on the impact of PA on physical performance and health outcomes in older age.

Key words: Epidemiology, physical function, sedentary, accelerometry, gait speed 


\section{Highlights}

- Achieving at least 5 minutes/day of MVPA related to better physical function.

- Accumulating more steps/day related to greater gait speed in adults $\geq 75$ years.

- Only $15 \%$ of adults $\geq 75$ years met the Physical Activity Guidelines for Americans. 


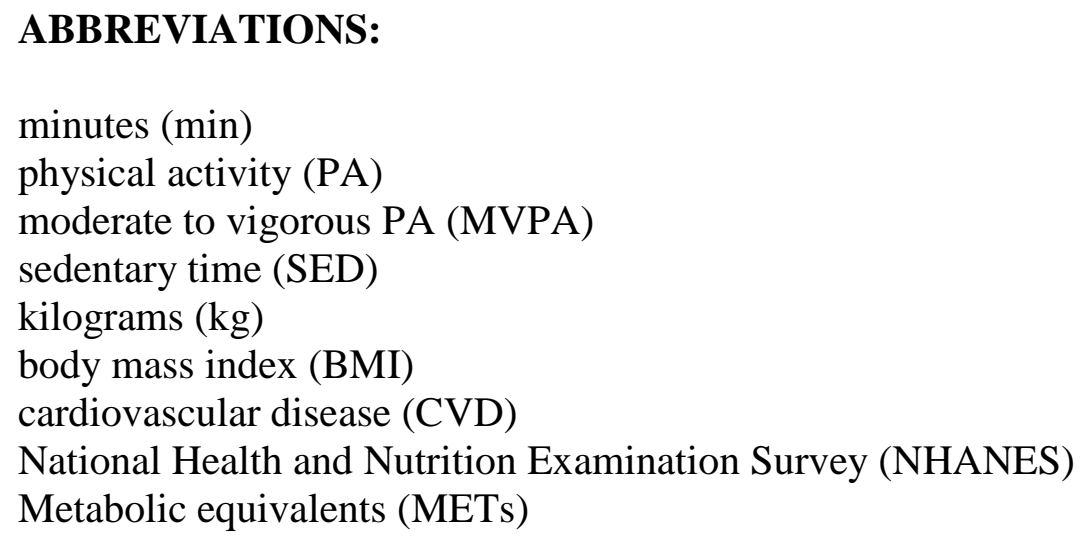




\section{Introduction}

The decline of physical function predicts disability and mortality in older adults. $(1,2)$ Over the next two decades, it is expected that $>15$ million older adults in the United States will be living with mobility disability (defined as inability to walk $1 / 4$ mile), potentially adding an estimated $\$ 42$ billion to annual health care costs. $(2,3)$ One of the leading factors related to years lived with physical disability is physical inactivity.(4) By the same token, intervention programs to increase physical activity (PA) have emerged as a potentially effective prevention strategy for decreasing incident mobility disability.(5, 6) ..(7) Objective accelerometry data from nationally representative samples have revealed that few older adults meet the traditional 150 minutes (min)/week of moderate to vigorous PA (MVPA) Guidelines for Americans from 2008. $(7,8)$ New national guidelines for PA released in 2018 recommend incremental PA for older adults who are not able to meet the MVPA Guideline and suggest that some PA is better than none.(9) However, exact intensities and durations of PA associated with mobility and physical performance in older age have not been well characterized.

Recent data suggests that maintaining a favorable balance of more light intensity PA and less sedentary time (SED) may decrease mortality in older adults.(10,11) In older age, PA begins to decline and SED increases.(12) These lifestyle changes have also been associated with worse self reported mobility and health status.(13-16) There is also prior evidence regarding the association between objective measures of PA and SED with objective physical performance measures.(5, 17-22) Previous studies have suggested that SED may actually be a separate risk factor for disability, regardless of the amount of PA obtained,(21) possibly through independent mechanisms involving the influence of SED on metabolic regulation in muscle tissue.(23) Few prior studies have excluded participants with mobility disability, $(5,20,22)$ who have 
significantly higher SED, even after adjusting for MVPA;(21) therefore, it is unclear whether reverse causality (i.e., the effect of a severe mobility disability on PA and SED behavior) may have influenced prior results.

For the current investigation, we examined whether PA and SED were associated with physical performance in cross-sectional analyses, at a time before participants developed overt mobility disability in a community-based cohort study. Our design minimizes, but does not remove the potential influence of reverse causality. Secondarily, we assessed whether these associations differed by age group. We hypothesized that the total volume of PA (measured as total steps per day) and lower SED would correlate with physical performance in older adulthood. The ability to distinguish PA durations and intensities that are related to physical performance outcomes across middle and older age ranges may provide evidence supporting the establishment of more attainable goals for total PA and SED in the PA Guidelines for older Americans, which currently focus on achieving MVPA.

\section{Methods}

The Framingham Offspring Study $(\mathrm{N}=5124)$ is an ongoing longitudinal cohort study that began in 1971.(24) In 1994, the Omni Cohort 1 study was initiated, consisting of residents of Framingham who identified as members of a minority group $(\mathrm{N}=507) .(25)$ The present study includes participants who attended Offspring examination cycle 9 (N=2430) or Omni Cohort 1 examination cycle 4 ( $N=301)$ in 2011 to 2014, completed the self-reported mobility questionnaire and objectively measured physical performance battery, and agreed to wear the accelerometer to measure objective PA $(\mathrm{N}=1845)$. Participants were excluded if they wore the accelerometer for $<4$ valid days $(n=390)$, were $<50$ years of age $(n=6)$, self-reported having a 
mobility disability $(n=82)$ or if they were missing covariate data $(n=15)$. The final sample size was 1,352 (approximately 50\% of attendees at the 2011-2014 examinations). Mobility disability was defined as self-reported inability to walk one half mile or climb one flight of stairs. Although exclusion for self-reported mobility disability likely did not completely remove individuals with disabilities, our goal was to limit potential bias toward self-exclusion and to limit the effect of reverse causation in our results, which cannot be completely eliminated. Analyses showing demographics and PA behavior in participants excluded for mobility disability is reported in Supplemental Table 1. All participants provided written informed consent, and the institutional review board at Boston University Medical Center approved the study protocols.

\section{Physical Performance}

We assessed gait speed using the faster of two trials on a 4-meter (m) course walked at usual pace. $(1,26,27)$ We also assessed lower body strength by measuring the ability and time taken to stand five times from the sitting position in a straight-backed chair with arms folded, termed the chair stand test/task.(28) Handgrip strength was assessed by measuring the highest force generated (in kilograms $[\mathrm{kg}]$ ) by participants asked to squeeze a JAMAR dynamometer (Sammons Preston/JLW Instruments, Chicago, IL, USA) as hard as possible, three times in each hand.(29)

\section{Physical Activity Accelerometry}

All participants were asked to wear an omnidirectional accelerometer (Actical model no. 1980200-00; Philips Respironics) on the hip for 8 days during all hours throughout the day and night (except when bathing).(30) Recorded signals (within 0.5-3 Hz and accelerations/decelerations within 0.05-2 g) were grouped into "counts" or "steps" at 30 second (s) intervals and averaged over 1 min intervals. Data were processed for quality control and analyzed at the Framingham 
Heart Study using customized software (Kinesoft, version 3.3.63), during which the first day of wear was removed from the dataset.(30) The measurement of steps by Actical devices has been externally validated.(31)

Accelerometer data was considered valid if the device was worn for $\geq 10$ hours per day for at least 4 days, not including the first day of wear on which the device was given out. Nonwear time was removed during data processing (defined as 60 consecutive min of zero counts, allowing for 2-min interruption periods). SED was defined as $<200$ counts/min and light intensity PA was defined as 200-1486 counts/min.(30) SED and light intensity PA were only considered during wear time occurring between 6 AM-10 PM, and were reported as a percentage of wear time (\%SED and \%Light Intensity PA). Due to high correlation between \%SED and \%Light Intensity PA ( $\mathrm{r}=-0.90, \mathrm{p}<0.0001$, Supplemental Table 2), only \%SED results were displayed in the main document. MVPA was defined as >1486 counts/min.(32, 33) MVPA and total steps per day were considered during any time of the day.

\section{Covariates}

Covariates included body mass index (BMI), current smoking, stage II hypertension (using the 2017 American College of Cardiology/American Heart Association Hypertension Guideline, systolic blood pressure $\geq 140 \mathrm{mmHg}$ or diastolic blood pressure $\geq 90 \mathrm{mmHg}$ ),(34) diabetes mellitus (fasting blood glucose $\geq 126 \mathrm{mg} / \mathrm{dL}$, or diabetes medications), prevalent cardiovascular disease (CVD), and prevalent cancer.

\section{Statistical Analysis}

Descriptive statistics were presented overall and by age group as follows: means and standard deviations for continuous variables and frequencies for the categorical variables (Table 1). Medians and quartiles 1 and 3 are also presented in Supplemental Table 3. Chair stand time and 
MVPA were log-transformed for the analysis. For each outcome (gait speed, chair stand time, and sex-specific handgrip strength) and each of the following predictors (SED, MVPA, and steps), two sets of linear regression models were performed. The first set was adjusted for age, sex, cohort, season, wear time and residence in New England (vs. elsewhere). The second set was additionally adjusted for BMI, current smoking, hypertension, diabetes mellitus, CVD, and cancer. For the MVPA and SED models, a third model was added, additionally adjusting SED models for MVPA and MVPA models for SED to test which PA component was the more predominant factor related to physical performance. Each set of models was repeated stratifying by age group (50-64, 65-74, and $\geq 75$ years). Partial Pearson correlation coefficients between the physical activity variables adjusting for age, sex, cohort, season, wear time and residence in New England were also presented. For primary analyses, an alpha value of 0.05 was our threshold for statistical significance. For the interactions, alpha of 0.10 was set as the threshold.

\section{Results}

Only $38 \%$ of adults aged 50-64 years achieved the PA Guidelines of performing 150 min of MVPA per week (calculated using the average MVPA min/day multiplied by 7). Guideline achievement dropped to $15 \%$ in participants $\geq 75$ years (Table 1). Approximately $50 \%$ of participants $\geq 75$ years achieved less than 5 min of MVPA per day (Table 1 and Figure 1). In data standardized to a 16-hour day, average SED increased across our age categories by almost one hour due to decreases in MPVA (by $\sim 13 \mathrm{~min} /$ day) and light intensity PA (by $\sim 2 \mathrm{~min} /$ day). Average gait speed decreased from 1.23 to $1.08 \mathrm{~m} / \mathrm{s}$ across age groups. The percent of participants in each age group achieving PA and physical performance categories are displayed in Figure 1 and Supplemental Figure 1. By comparison, for participants that were excluded 
from the main results of this investigation due to self-reported mobility disability (mean age $73.7 \pm 8.3$ years), only $2 \%$ achieved the PA Guidelines, $80 \%$ did not even achieve 5 min MVPA/day, and physical performance of the lower body (gait speed and chair stand time) were poorer than those included in the investigation (Supplemental Table 1).

In participants without mobility disability, MVPA was associated with a higher gait speed, lower time to complete five chair-stands $(\beta=0.041 \pm 0.006$ and $\beta=-0.044 \pm 0.008$, both $\mathrm{p}<0.0001$, Table 2) and higher handgrip strength in men $(\beta=1.25 \pm 0.42, \mathrm{p}=0.003)$ and women $(\beta=1.03 \pm 0.26, \mathrm{p}<0.0001)$ in multivariable models including adjustment for SED. No statistical interactions by age group were detected for the association of MVPA with any physical performance variable. Similarly, the number of steps taken per day was also associated with better performance on the chair-stand task (lower time) in the full sample $(\beta=-0.007 \pm 0.002$, $\mathrm{p}=0.0002$, Table 3), without evidence of a statistical age interaction.

Interactions by age were observed for the relations of steps and SED to many of the physical performance measures $(\mathrm{p}<0.10$, Table 3). Higher total activity (measured by steps/day) and lower SED were associated with higher gait speed in participants $\geq 75$ years $(\beta=0.009 \pm 0.003$, $p=0.006 ; \beta=-0.007 \pm 0.002, p=0.0003)$, but the relation with SED was no longer significant after adjusting for MVPA $(\beta=-0.002 \pm 0.002, \mathrm{p}=0.327)$. Similarly, associations of SED with worse performance on chair stand (higher time) and handgrip strength (in women only), were no longer significant after adjustment for MVPA ( $p>0.20)$. In contrast, in men, there were unexpected relations of lower steps and higher SED to higher handgrip strength in middle age (50-64 years: $\beta=-0.54 \pm 0.20, p=0.007 ; \beta=0.420 \pm 0.123, p=0.0008)$ and in older age $(\geq 75$ years: $\beta=0.303 \pm 0.120$, $\mathrm{p}=0.013)$. 
Individuals achieving at least $5 \mathrm{~min} /$ day of MVPA have $0.062 \pm 0.013 \mathrm{~m} / \mathrm{s}$ greater gait speed than those with $<5 \mathrm{~min} /$ day of MVPA $(\mathrm{p}<0.0001)$ across middle and older age (Figure 2 and Table 2). For adults $\geq 75$ years, the magnitude of the association for every 5000 more steps related to approximately $0.045 \mathrm{~m} / \mathrm{s}$ higher gait speed (Table 3 displays $\beta$ for every 1000 steps), which was slightly smaller than the magnitude of the association of achieving $\geq 5 \mathrm{~min} /$ day MVPA. Similarly, for participants $\geq 75$ years old, the relation of SED to gait speed was equivalent to $\sim 0.04 \mathrm{~m} / \mathrm{s}$ for every hour less SED per day $(\sim 0.007 \mathrm{~m} / \mathrm{s}$ for every $10 \mathrm{~min}$ less SED), but after adjusting for MVPA these relations were no longer significant. Figure 2 also demonstrates that $\geq 5 \mathrm{~min} /$ day MVPA is associated with approximately $\sim 1 \mathrm{~s}$ lower chair stand time, better performance than achieving $<5$ min/day MVPA (after reversing the logtransformation on chair stand time, Table 2, $\mathrm{p}<0.0001$ ).

\section{Discussion}

Our community-based study of middle-aged and older adults free of mobility disability demonstrates several important findings with respect to PA and physical function. First, both total PA (step accumulation) and MVPA were related to physical performance of the lower body, including gait speed and the chair stand task. For the association of total PA with gait speed, significance was only observed in persons $\geq 75$ years. MVPA was also positively associated with handgrip strength. Second, we observed associations of SED with physical performance of the lower body, which did not remain significant after adjustment for MVPA. The 2018 PA Guidelines ( $2^{\text {nd }}$ edition) continue to focus on achievement of MVPA goals for adults $(\geq 150 \mathrm{~min}$ MVPA/week or $\geq 21.4$ min MVPA/day), young and old alike, based on a consensus from the literature and experts.(9) But these new guidelines now also include advice for achieving 
incremental PA, stating that "even 5 minutes of PA has real health benefits."(9) The data we present supports these current recommendations, identifying associations of the total volume of PA, measured by step count, and much lower MVPA levels (achieving just 5 min MVPA per day) with physical performance. Our cross-sectional data suggests that even incremental differences in PA volume and intensity may play a role in physical function, and vice versa.

We reported that the relative importance of achieving small amounts of MVPA or taking more steps appears to be more prominent than achieving a favorable balance in the proportion of time spent in SED in terms of the association with gait speed. To put our results into context, previous studies have identified that a PA intervention can improve gait speed(6) and that small changes in gait speed $(0.1 \mathrm{~m} / \mathrm{s}$ increments) were associated with better survival.(1) Small differences in accelerometer-determined light intensity activity and MVPA were also related to lower mortality rates in 3-year follow-up analysis in the Women's Health Initiative.(35) Furthermore, change in gait speed at even smaller increments $(0.03-0.05 \mathrm{~m} / \mathrm{s})$ have been estimated to be clinically meaningful in subjective self-assessments.(36) In our investigation, achieving at least $5 \mathrm{~min} /$ day of MVPA was associated with $0.062 \mathrm{~m} / \mathrm{s}$ greater gait speed, across the age ranges. For older adults ( $\geq 75$ years), every 5000 more steps/day achieved was related to approximately $0.045 \mathrm{~m} / \mathrm{s}$ greater gait speed. Because our population of adults $\geq 75$ years take only 5577 steps/day on average, doubling one's total PA to make a modest clinical impact on gait speed may not be a attainable goal.

Although the size of the association with SED appeared robust for participants $\geq 75$ years old ( $\sim 0.04 \mathrm{~m} / \mathrm{s}$ for every hour less SED), after adjusting for MVPA these relations were no longer significant. However, it is important to remember that we have only presented data from participants not reporting mobility disability and may have higher physical function. Our goal 
was to limit the effect of reverse causation by participants with severe mobility disability, although reverse causation likely still does play some role in our findings. More research is needed with data from longitudinal design to further understand the role of reverse causality. Previous literature suggests that SED is strongly related to functional/mobility disability, $(21,37)$ which we confirmed in the current investigation. We observed higher SED and much lower PA in participants with mobility disability (excluded from our main investigation, but presented in supplemental materials). We were interested in assessing associations of PA and SED with physical performance at a time before participants developed mobility disability.

Recent studies have identified an association of SED with gait speed(19) and other measures of physical function, $(18,19)$ which remained after adjusting for MVPA. Although investigators in these studies adjusted for wear time rather than index SED to wear time as in our investigation, neither previous studies nor the current study are able to account for residual confounding by wear time. It is clear that wear time has a major influence on total SED.(17) Additionally, the study that observed an association of SED with gait speed was in much older adults (mean age 84 years) living in retirement communities with low levels of MVPA (mean 8.7 min/day) and very poor performance on gait speed task (mean $0.83 \mathrm{~m} / \mathrm{s}) .(19)$ Therefore, although a large proportion of our oldest sample had low MVPA (i.e., $50 \%$ of adults our sample $\geq 75$ years had $<5 \mathrm{~min}$ /day MVPA), our full investigation is not completely comparable to the retirement communities study. Instead, our results are in agreement with a separate investigation in a British cohort by Keevil et. al., demonstrating that the association of the proportion of time spent in SED relates to poorer gait speed, but in interaction analyses they observed an association of SED with gait speed, chair stand time, and handgrip strength in those achieving less than 19 min MVPA/day.(17) We must also recognize that individuals with mobility disability were not 
excluded from this study, but were excluded from our study, possibly contributing to slightly different results observed in our investigation. An important future direction may be to understand the relation of SED to physical performance in participants with low MVPA.

We also reported an unexpected result that we are unable to explain, which was that lower total step count and higher SED related to higher handgrip strength in middle-aged men. One explanation may stem from the known association of BMI with both higher handgrip strength and higher SED.(20, 38) Therefore, although we adjusted for BMI, our observations could be a result of residual confounding by body composition or due to weight lifting or other non-ambulatory activities that are not assessed by accelerometry. Other studies similar to ours did not observe these significant associations in their study samples, but also did not test for interactions by age group. $(17,20)$ We may have identified a novel association of SED with handgrip strength in middle-aged men, which could theoretically be due to behavioral or demographic determinants of SED, possibly including the sedentary nature of certain occupations or other hobbies/interests. These relationships require further investigation.

It is clear that there is a shift towards a less active and a more SED lifestyle in older age but more studies are needed to understand whether the pattern and duration of SED has an impact on healthy aging and physical function. It will also be important to understand potential causes of increased SED behavior in older age that may be unrelated to mobility, such as changes in employment status and social behavior. Furthermore, our decision to standardize wear time to a 16 hour day may introduce some bias because SED may not be equally distributed throughout the day. However, it was important to standardize wear time because of the strong correlation of SED with device wear time that we reported in the supplemental material. We must also acknowledge the potential influence of selection bias (including survival bias), which 
limits our analysis to individuals who have survived and agreed to participate in the ninth Offspring examination. Individuals that participate in accelerometry studies are typically more healthy than those who opt out.(39)

The current investigation was a cross-sectional observational study and, therefore, precludes inferences of causality or temporality. The interpretation that most likely explains our results is a bi-directional association, in which declining PA and physical function both have causal pathways that impact one another.(17) While the large sample size allowed us to account for covariates, others, such as chronic obstructive pulmonary disease, arthritis, and other pain, may account for some of the observed associations. This study may also lack generalizability to individuals of non-European ancestry. Individuals of non-European ancestry are included in the Omni cohort, but these numbers are too small to analyze separately.

It is also important to mention that the ranges of steps we observed in our study were higher than study samples of similar ages.(40) Average reported steps/day for the National Health and Nutrition Examination Survey (NHANES, 2005-2006) were consistently >2,500 steps/day lower for each age group (NHANES ages 60-64 years: 5444 steps/day; age 65-74 years: 4030 steps/day; ages 75-79: 2519 steps/day; ages 80-84 years: 1928 steps/day).(40) NHANES and other studies have used different data censoring methods(40-42) and different accelerometer devices, which have different sensitivity to very low walking speeds (low frequency movement);(43) thus, influencing absolute levels of step accumulation, which should, therefore, be considered cautiously. Actical devices have been demonstrated to be more sensitive to low frequency movement than other popular accelerometers, recording a higher percentage of steps accumulated at slower walking speeds.(43) Therefore, Actical devices may be more suited 
to older adults with slower walking speeds. Notably, our average steps/day were similar to those reported by the Physical Performance Across the Life-span Study.(22)

It is also difficult to compare physical function across different large studies due to differences in testing protocols.(44) Comparative physical performance measures were similar or slightly faster for gait speed and chair stand time compared to other reported reference values by age group including NHANES, $(22,45,46)$ but our study sample had lower hand grip strength than other reference groups.(47)

The PA Guidelines for Americans have historically focused predominantly on MVPA.(7, 9) Among Framingham Offspring Study participants $\geq 75$ years old, only $15 \%$ were meeting the PA Guidelines and 50\% were not even performing an average of 5 min of MVPA per day. If we focus only on MVPA, it appears that older Americans are inactive, a behavior which is associated with increased mortality rates.(48) However, it is possible that the assessment of PA intensity in older adults requires more sensitive investigation. MVPA is defined as any PA performed at a work rate $\geq 3$ metabolic equivalents (METs) and is most commonly defined as activity above the 1400-2500 counts/min accelerometer cutpoint in young and middle aged adults. $(30,32,33,49)$ In contrast, older adults often have lower fitness and may achieve 3 METs of work at much lower counts of accelerometer movement. $(50,51)$ Therefore, PA performed at a lower accelerometer count threshold, may be more appropriate to determine the proportion of older adults meeting PA MET requirements. $(12,52,53)$ This is an active area of research and other groups are exploring different cutpoints,(35) but for the current study we chose to keep a consistent MVPA count threshold across all age groups to test associations related to different intensities of movement rather than modifying cutpoints that would define MVPA for each age 
group. Instead, our analysis of total step count may provide a less biased measure that accumulates total PA regardless of intensity.

\section{Conclusions}

Our cross-sectional study across middle and older ages demonstrated consistent associations of higher MVPA, even just 5 min/day MVPA, with better physical performance and some association of total step accumulation with physical performance. This result is in agreement with the new PA Guidelines which promote the concept that some PA is better than none. Associations of SED with physical performance of the lower body did not remain significant after adjustment for MVPA. These data warrant future research on the influence of different intensities of PA on physical function and health outcomes in the elderly.

\section{Funding}

The work was supported by funding from the National Institutes of Health (NIH) (N01HC25195, HHSN268201500001I; R01-AG047645; R01-HL131029; R56-AG029451); and American Heart Association (15GPSGC24800006 and 16MCPRP30310001). Dr. Vasan is supported in part by the Evans Medical foundation and the Jay and Louis Coffman Endowment, Department of Medicine, BUSM. 
References

1. Studenski S, Perera S, Patel K, et al. Gait speed and survival in older adults. Jama. 2011;305(1):50-8.

2. Hardy SE, Kang Y, Studenski SA, Degenholtz HB. Ability to walk $1 / 4$ mile predicts subsequent disability, mortality, and health care costs. Journal of general internal medicine. 2011;26(2):130-5. Epub 2010/10/26. doi: 10.1007/s11606-010-1543-2. PubMed PMID: 20972641; PubMed Central PMCID: PMCPmc3019329.

3. Cummings SR, Studenski S, Ferrucci L. A diagnosis of dismobility--giving mobility clinical visibility: a Mobility Working Group recommendation. Jama. 2014;311(20):2061-2. Epub 2014/04/26. doi: 10.1001/jama.2014.3033. PubMed PMID: 24763978; PubMed Central PMCID: PMCPMC5012417.

4. The state of US health, 1990-2010: burden of diseases, injuries, and risk factors. Jama. 2013;310(6):591-608. Epub 2013/07/12. doi: 10.1001/jama.2013.13805. PubMed PMID: 23842577.

5. Pahor M, Guralnik JM, Ambrosius WT, et al. Effect of structured physical activity on prevention of major mobility disability in older adults: the LIFE study randomized clinical trial. JAMA. 2014;311(23):2387-96. doi: 10.1001/jama.2014.5616. PubMed PMID: 24866862.

6. Espeland MA, Lipska K, Miller ME, et al. Effects of Physical Activity Intervention on Physical and Cognitive Function in Sedentary Adults With and Without Diabetes. J Gerontol A Biol Sci Med Sci. 2017;72(6):861-6. Epub 2016/09/04. doi: 10.1093/gerona/glw179. PubMed PMID: 27590629.

7. Physical Activity Guidelines Advisory Committee, . Physical Activity Guidelines Advisory Committee report, 2008. Washington DC: US Department of Health and Human Services; 2008.

8. Tucker JM, Welk GJ, Beyler NK. Physical activity in U.S.: adults compliance with the Physical Activity Guidelines for Americans. American journal of preventive medicine. 2011;40(4):454-61. Epub 2011/03/17. doi: 10.1016/j.amepre.2010.12.016. PubMed PMID: 21406280.

9. Services USDoHaH. Physical Activity Guidelines for Americans, 2nd edition. Washington, DC: US Department of Health and Human Services. 2018.

10. Dohrn IM, Sjostrom M, Kwak L, Oja P, Hagstromer M. Accelerometer-measured sedentary time and physical activity-A 15 year follow-up of mortality in a Swedish population-based cohort. Journal of science and medicine in sport / Sports Medicine Australia. 2017. Epub 2017/11/13. doi:

10.1016/j.jsams.2017.10.035. PubMed PMID: 29128418.

11. Hamer M, de Oliveira C, Demakakos P. Non-exercise physical activity and survival: English longitudinal study of ageing. American journal of preventive medicine. 2014;47(4):452-60. Epub 2014/07/23. doi: 10.1016/j.amepre.2014.05.044. PubMed PMID: 25049216.

12. Martin KR, Koster A, Murphy RA, et al. Changes in daily activity patterns with age in u.s. Men and women: national health and nutrition examination survey 2003-04 and 2005-06. J Am Geriatr Soc. 2014;62(7):1263-71. doi: 10.1111/jgs.12893. PubMed PMID: 24962323.

13. Buman MP, Hekler EB, Haskell WL, et al. Objective light-intensity physical activity associations with rated health in older adults. Am J Epidemiol. 2010;172(10):1155-65. Epub 2010/09/17. doi: 10.1093/aje/kwq249. PubMed PMID: 20843864; PubMed Central PMCID: PMCPmc3004766.

14. Gennuso KP, Thraen-Borowski KM, Gangnon RE, Colbert LH. Patterns of sedentary behavior and physical function in older adults. Aging clinical and experimental research. 2016;28(5):943-50. Epub 2015/05/30. doi: 10.1007/s40520-015-0386-4. PubMed PMID: 26022448.

15. Marques EA, Baptista F, Santos DA, Silva AM, Mota J, Sardinha LB. Risk for losing physical independence in older adults: The role of sedentary time, light, and moderate to vigorous physical activity. Maturitas. 2014. doi: 10.1016/j.maturitas.2014.06.012. PubMed PMID: 25022468.

16. Marques EA, Baptista F, Santos DA, Silva AM, Mota J, Sardinha LB. Risk for losing physical independence in older adults: the role of sedentary time, light, and moderate to vigorous physical 
activity. Maturitas. 2014;79(1):91-5. Epub 2014/07/16. doi: 10.1016/j.maturitas.2014.06.012. PubMed PMID: 25022468.

17. Keevil VL, Cooper AJ, Wijndaele K, et al. Objective Sedentary Time, Moderate-to-Vigorous Physical Activity, and Physical Capability in a British Cohort. Medicine and science in sports and exercise. 2016;48(3):421-9. Epub 2015/10/27. doi: 10.1249/mss.0000000000000785. PubMed PMID: 26501232; PubMed Central PMCID: PMCPMC4762192.

18. Santos DA, Silva AM, Baptista F, et al. Sedentary behavior and physical activity are independently related to functional fitness in older adults. Experimental gerontology. 2012;47(12):90812. Epub 2012/08/14. doi: 10.1016/j.exger.2012.07.011. PubMed PMID: 22884978.

19. Rosenberg DE, Bellettiere J, Gardiner PA, Villarreal VN, Crist K, Kerr J. Independent Associations Between Sedentary Behaviors and Mental, Cognitive, Physical, and Functional Health Among Older Adults in Retirement Communities. J Gerontol A Biol Sci Med Sci. 2016;71(1):78-83. Epub 2015/08/15. doi: 10.1093/gerona/glv103. PubMed PMID: 26273024; PubMed Central PMCID: PMCPMC4861254. 20. Bann D, Hire D, Manini T, et al. Light Intensity physical activity and sedentary behavior in relation to body mass index and grip strength in older adults: cross-sectional findings from the Lifestyle Interventions and Independence for Elders (LIFE) study. PLoS One. 2015;10(2):e0116058. Epub 2015/02/04. doi: 10.1371/journal.pone.0116058. PubMed PMID: 25647685; PubMed Central PMCID: PMCPMC4315494.

21. Dunlop DD, Song J, Arnston EK, et al. Sedentary time in US older adults associated with disability in activities of daily living independent of physical activity. Journal of physical activity \& health. 2015;12(1):93-101. Epub 2014/02/11. doi: 10.1123/jpah.2013-0311. PubMed PMID: 24510000; PubMed Central PMCID: PMCPMC4153790.

22. Hall KS, Cohen HJ, Pieper CF, et al. Physical Performance Across the Adult Life Span: Correlates With Age and Physical Activity. J Gerontol A Biol Sci Med Sci. 2017;72(4):572-8. Epub 2016/07/01. doi: 10.1093/gerona/glw120. PubMed PMID: 27356977; PubMed Central PMCID: PMCPMC6075535.

23. Bey L, Hamilton MT. Suppression of skeletal muscle lipoprotein lipase activity during physical inactivity: a molecular reason to maintain daily low-intensity activity. J Physiol. 2003;551(Pt 2):673-82. Epub 2003/06/20. doi: 10.1113/jphysiol.2003.045591. PubMed PMID: 12815182; PubMed Central PMCID: PMCPMC2343229.

24. Kannel WB, Feinleib M, McNamara PM, Garrison RJ, Castelli WP. An investigation of coronary heart disease in families. The Framingham offspring study. Am J Epidemiol. 1979;110(3):281-90. Epub 1979/09/01. PubMed PMID: 474565.

25. Quan SF, Howard BV, Iber C, et al. The Sleep Heart Health Study: design, rationale, and methods. Sleep. 1997;20(12):1077-85. Epub 1998/03/11. PubMed PMID: 9493915.

26. Studenski S, Perera S, Wallace $D$, et al. Physical performance measures in the clinical setting. J Am Geriatr Soc. 2003;51(3):314-22. Epub 2003/02/18. PubMed PMID: 12588574.

27. Guralnik JM, Ferrucci L, Pieper CF, et al. Lower extremity function and subsequent disability: consistency across studies, predictive models, and value of gait speed alone compared with the short physical performance battery. J Gerontol A Biol Sci Med Sci. 2000;55(4):M221-31. Epub 2000/05/16. PubMed PMID: 10811152.

28. Riskowski JL, Hagedorn TJ, Dufour AB, Hannan MT. Functional foot symmetry and its relation to lower extremity physical performance in older adults: the Framingham Foot Study. Journal of biomechanics. 2012;45(10):1796-802. Epub 2012/05/09. doi: 10.1016/j.jbiomech.2012.04.019. PubMed PMID: 22560642; PubMed Central PMCID: PMCPMC3376228.

29. Murabito JM, Rong J, Lunetta KL, et al. Cross-sectional relations of whole-blood miRNA expression levels and hand grip strength in a community sample. Aging cell. 2017;16(4):888-94. Epub 2017/06/10. doi: 10.1111/acel.12622. PubMed PMID: 28597569; PubMed Central PMCID: PMCPMC5506437. 
30. Glazer NL, Lyass A, Esliger DW, et al. Sustained and shorter bouts of physical activity are related to cardiovascular health. Medicine and science in sports and exercise. 2013;45(1):109-15. doi:

10.1249/MSS.0b013e31826beae5. PubMed PMID: 22895372; PubMed Central PMCID: PMCPMC4166425

31. Esliger DW, Probert A, Connor Gorber S, Bryan S, Laviolette M, Tremblay MS. Validity of the Actical accelerometer step-count function. Medicine and science in sports and exercise. 2007;39(7):1200-4. doi: 10.1249/mss.0b013e3804ec4e9. PubMed PMID: 17596790.

32. Crouter SE, Bassett DR, Jr. A new 2-regression model for the Actical accelerometer. British journal of sports medicine. 2008;42(3):217-24. Epub 2007/09/01. doi: 10.1136/bjsm.2006.033399. PubMed PMID: 17761786.

33. Heil DP. Predicting activity energy expenditure using the Actical activity monitor. Research quarterly for exercise and sport. 2006;77(1):64-80. Epub 2006/05/02. PubMed PMID: 16646354.

34. Whelton PK, Carey RM, Aronow WS, et al. 2017

ACC/AHA/AAPA/ABC/ACPM/AGS/APhA/ASH/ASPC/NMA/PCNA Guideline for the Prevention, Detection, Evaluation, and Management of High Blood Pressure in Adults: A Report of the American College of Cardiology/American Heart Association Task Force on Clinical Practice Guidelines. J Am Coll Cardiol. 2017. Epub 2017/11/18. doi: 10.1016/j.jacc.2017.11.006. PubMed PMID: 29146535.

35. LaMonte MJ, Buchner DM, Rillamas-Sun E, et al. Accelerometer-Measured Physical Activity and Mortality in Women Aged 63 to 99. J Am Geriatr Soc. 2017. Epub 2017/11/17. doi: 10.1111/jgs.15201. PubMed PMID: 29143320.

36. Kwon $S$, Perera $S$, Pahor $M$, et al. What is a meaningful change in physical performance? Findings from a clinical trial in older adults (the LIFE-P study). J Nutr Health Aging. 2009;13(6):538-44. Epub 2009/06/19. PubMed PMID: 19536422; PubMed Central PMCID: PMCPMC3100159.

37. Gennuso KP, Gangnon RE, Matthews CE, Thraen-Borowski KM, Colbert LH. Sedentary behavior, physical activity, and markers of health in older adults. Medicine and science in sports and exercise. 2013;45(8):1493-500. Epub 2013/03/12. doi: 10.1249/MSS.0b013e318288a1e5. PubMed PMID: 23475142.

38. Fried LP, Tangen CM, Walston J, et al. Frailty in older adults: evidence for a phenotype. J Gerontol A Biol Sci Med Sci. 2001;56(3):M146-56. Epub 2001/03/17. PubMed PMID: 11253156.

39. Spartano NL, Stevenson MD, Xanthakis V, et al. Associations of objective physical activity with insulin sensitivity and circulating adipokine profile: the Framingham Heart Study. Clinical obesity. 2017;7(2):59-69. Epub 2017/01/24. doi: 10.1111/cob.12177. PubMed PMID: 28112860; PubMed Central PMCID: PMCPMC5339058.

40. Tudor-Locke C, Schuna JM, Jr., Barreira TV, et al. Normative steps/day values for older adults: NHANES 2005-2006. J Gerontol A Biol Sci Med Sci. 2013;68(11):1426-32. Epub 2013/08/06. doi: 10.1093/gerona/glt116. PubMed PMID: 23913932.

41. Tudor-Locke C, Johnson WD, Katzmarzyk PT. Accelerometer-determined steps per day in US adults. Medicine and science in sports and exercise. 2009;41(7):1384-91. Epub 2009/06/12. doi: 10.1249/MSS.0b013e318199885c. PubMed PMID: 19516163.

42. Chomistek AK, Yuan C, Matthews CE, et al. Physical Activity Assessment with the ActiGraph GT3X and Doubly Labeled Water. Medicine and science in sports and exercise. 2017;49(9):1935-44. Epub 2017/04/19. doi: 10.1249/mss.0000000000001299. PubMed PMID: 28419028; PubMed Central PMCID: PMCPMC5561512.

43. Feito Y, Bassett DR, Thompson DL, Tyo BM. Effects of body mass index on step count accuracy of physical activity monitors. Journal of physical activity \& health. 2012;9(4):594-600. Epub 2011/09/29. PubMed PMID: 21946229.

44. Rikli RE, Jones CJ. Functional fitness normative scores for community-residing older adults, ages 60-94. Journal of aging and physical activity. 1999;7(2):162-81. 
45. Steffen TM, Hacker TA, Mollinger L. Age- and gender-related test performance in communitydwelling elderly people: Six-Minute Walk Test, Berg Balance Scale, Timed Up \& Go Test, and gait speeds. Physical therapy. 2002;82(2):128-37. Epub 2002/02/22. PubMed PMID: 11856064.

46. Ostchega $Y$, Harris TB, Hirsch R, Parsons VL, Kington R, Katzoff M. Reliability and prevalence of physical performance examination assessing mobility and balance in older persons in the US: data from the Third National Health and Nutrition Examination Survey. J Am Geriatr Soc. 2000;48(9):1136-41. Epub 2000/09/13. PubMed PMID: 10983916.

47. Yoshimura $\mathrm{N}, \mathrm{Oka} \mathrm{H}$, Muraki S, et al. Reference values for hand grip strength, muscle mass, walking time, and one-leg standing time as indices for locomotive syndrome and associated disability: the second survey of the ROAD study. Journal of orthopaedic science : official journal of the Japanese Orthopaedic Association. 2011;16(6):768-77. Epub 2011/10/07. doi: 10.1007/s00776-011-0160-1. PubMed PMID: 21975521.

48. Koster A, Caserotti P, Patel KV, et al. Association of sedentary time with mortality independent of moderate to vigorous physical activity. PLoS One. 2012;7(6):e37696. doi: 10.1371/journal.pone.0037696. PubMed PMID: 22719846; PubMed Central PMCID: PMC3374810. 49. Freedson PS, Melanson E, Sirard J. Calibration of the Computer Science and Applications, Inc. accelerometer. Medicine and science in sports and exercise. 1998;30(5):777-81. Epub 1998/05/20. PubMed PMID: 9588623.

50. Ainsworth BE, Haskell WL, Whitt MC, et al. Compendium of physical activities: an update of activity codes and MET intensities. Medicine and science in sports and exercise. 2000;32(9 Suppl):S498504. Epub 2000/09/19. PubMed PMID: 10993420.

51. Corbett DB, Valiani V, Knaggs JD, Manini TM. Evaluating Walking Intensity with Hip-Worn Accelerometers in Elders. Medicine and science in sports and exercise. 2016;48(11):2216-21. Epub 2016/10/19. doi: 10.1249/mss.0000000000001018. PubMed PMID: 27327031; PubMed Central PMCID: PMCPMC5069122.

52. Gorman E, Hanson HM, Yang PH, Khan KM, Liu-Ambrose T, Ashe MC. Accelerometry analysis of physical activity and sedentary behavior in older adults: a systematic review and data analysis. European review of aging and physical activity : official journal of the European Group for Research into Elderly and Physical Activity. 2014;11:35-49. doi: 10.1007/s11556-013-0132-x. PubMed PMID: 24765212; PubMed Central PMCID: PMC3990855.

53. Schrack JA, Leroux A, Fleg JL, et al. Using Heart Rate and Accelerometry to Define Quantity and Intensity of Physical Activity in Older Adults. J Gerontol A Biol Sci Med Sci. 2018;73(5):668-75. Epub 2018/03/07. doi: 10.1093/gerona/gly029. PubMed PMID: 29509832; PubMed Central PMCID: PMCPMC5905658. 
Table 1. Study Sample Characteristics

\begin{tabular}{|c|c|c|c|c|}
\hline & $\begin{array}{l}\text { Overall } \\
(n=1352)\end{array}$ & $\begin{array}{l}\text { Age } 50-64 \\
(n=406)\end{array}$ & $\begin{array}{l}\text { Age } 65-74 \\
(n=662)\end{array}$ & $\begin{array}{l}\text { Age } \geq 75 \\
(n=284)\end{array}$ \\
\hline Age, years & $68.6 \pm 7.5$ & $60.0 \pm 3.4$ & $69.2 \pm 2.8$ & $79.2 \pm 3.7$ \\
\hline Women, \% & 54 & 55 & 54 & 52 \\
\hline Body mass index, $\mathrm{kg} / \mathrm{m}^{2}$ & $27.6 \pm 4.6$ & $27.7 \pm 5.1$ & $27.6 \pm 4.5$ & $27.1 \pm 4.1$ \\
\hline Current smoking, \% & 5 & 7 & 5 & 2 \\
\hline Hypertension, \% & 56 & 42 & 58 & 71 \\
\hline Diabetes, \% & 11 & 7 & 12 & 14 \\
\hline Cardiovascular disease, $\%$ & 12 & 6 & 12 & 19 \\
\hline Cancer, \% & 13 & 7 & 12 & 24 \\
\hline \multicolumn{5}{|c|}{ Physical Activity Variables } \\
\hline $\begin{array}{l}\text { Wear time, } \min / \text { day } \\
\text { during } 6 a m-10 p m \text {, a } 16 \text { h day }\end{array}$ & $749 \pm 71$ & $761 \pm 69$ & $747 \pm 72$ & $737 \pm 71$ \\
\hline $\begin{array}{l}\text { Sedentary time, \% wear time } \\
\text { (standardized to a } 16 \mathrm{~h} \text { day, h) }\end{array}$ & $\begin{array}{l}84.3 \pm 6.3 \\
(13.5 \pm 1.0)\end{array}$ & $\begin{array}{l}82.1 \pm 6.2 \\
(13.1 \pm 1.0)\end{array}$ & $\begin{array}{l}84.1 \pm 6.0 \\
(13.5 \pm 1.0)\end{array}$ & $\begin{array}{l}87.8 \pm 5.4 \\
(14.0 \pm 0.9)\end{array}$ \\
\hline $\begin{array}{l}\text { Light intensity PA, \% wear } \\
\text { time } \\
\text { (standardized to a } 16 \text { h day, h) }\end{array}$ & $\begin{array}{l}13.3 \pm 5 \\
(2.1 \pm 0.8)\end{array}$ & $\begin{array}{l}14.7 \pm 4.9 \\
(2.4 \pm 0.8)\end{array}$ & $\begin{array}{l}13.6 \pm 5.0 \\
(2.2 \pm 0.8)\end{array}$ & $\begin{array}{l}10.8 \pm 4.5 \\
(1.7 \pm 0.7)\end{array}$ \\
\hline Steps/day & $6927 \pm 3678$ & $7952 \pm 3636$ & $6877 \pm 3625$ & $5577 \pm 3410$ \\
\hline $\begin{array}{l}\text { MVPA time, } \min / \text { day } \\
\text { Mean } \pm S D \text { and (min, } \max )\end{array}$ & $\begin{array}{l}19 \pm 22 \\
(0,254) \\
\end{array}$ & $\begin{array}{l}25 \pm 25 \\
(0,254) \\
\end{array}$ & $\begin{array}{l}18 \pm 20 \\
(0,173) \\
\end{array}$ & $\begin{array}{l}12 \pm 17 \\
(0,96) \\
\end{array}$ \\
\hline $\begin{array}{l}\text { Achieved MVPA Guidelines } \\
\text { ( } \geq 150 \mathrm{~min} / \text { week), } \%\end{array}$ & 27 & 38 & 25 & 15 \\
\hline$\%$ with $<5$ min MVPA per day & 27 & 10 & 27 & 50 \\
\hline \multicolumn{5}{|c|}{ Physical Performance Variables } \\
\hline $\begin{array}{l}\text { Gait speed, } \mathbf{m} / \mathbf{s} \\
\text { Mean } \pm S D \text { and }(\min , \max )\end{array}$ & $\begin{array}{l}1.17 \pm 0.19 \\
(0.47,1.84)\end{array}$ & $\begin{array}{l}1.23 \pm 0.18 \\
(0.47,1.84)\end{array}$ & $\begin{array}{l}1.18 \pm 0.18 \\
(0.67,1.75)\end{array}$ & $\begin{array}{l}1.08 \pm 0.17 \\
(0.71,1.59)\end{array}$ \\
\hline $\begin{array}{l}\text { Chair Stands Time, } \mathbf{s} \\
\text { Mean } \pm \text { SD and (min, max) }\end{array}$ & $\begin{array}{l}9.9 \pm 2.6 \\
(4.4,29.8)\end{array}$ & $\begin{array}{l}9.3 \pm 2.5 \\
(4.6,29.8)\end{array}$ & $\begin{array}{l}9.8 \pm 2.4 \\
(4.4,19.5)\end{array}$ & $\begin{array}{l}11.2 \pm 3.0 \\
(5.1,25.3)\end{array}$ \\
\hline $\begin{array}{l}\text { Hand grip strength for men, kg } \\
\text { Mean } \pm S D \text { and (min, max) }\end{array}$ & $\begin{array}{l}39.1 \pm 8.7 \\
(16,68)\end{array}$ & $\begin{array}{l}42.9 \pm 9.2 \\
(19,68)\end{array}$ & $\begin{array}{l}39.2 \pm 7.8 \\
(16,59)\end{array}$ & $\begin{array}{l}33.8 \pm 6.8 \\
(16,54)\end{array}$ \\
\hline $\begin{array}{l}\text { Hand grip strength for women, } \\
\text { kg } \\
\text { Mean } \pm \text { SD and (min, max) }\end{array}$ & $\begin{array}{l}23.3 \pm 5.7 \\
(6,44)\end{array}$ & $\begin{array}{l}26.1 \pm 5.3 \\
(12,39)\end{array}$ & $\begin{array}{l}22.9 \pm 5.2 \\
(6,44)\end{array}$ & $\begin{array}{l}20.0 \pm 5.1 \\
(10,34)\end{array}$ \\
\hline
\end{tabular}

Abbreviations: physical activity (PA); moderate-to-vigorous physical activity (MVPA); kilograms (kg); meters $(\mathrm{m})$; seconds (s); minutes (min) 
Figure 1. Percent of participants in each age group achieving physical activity categories
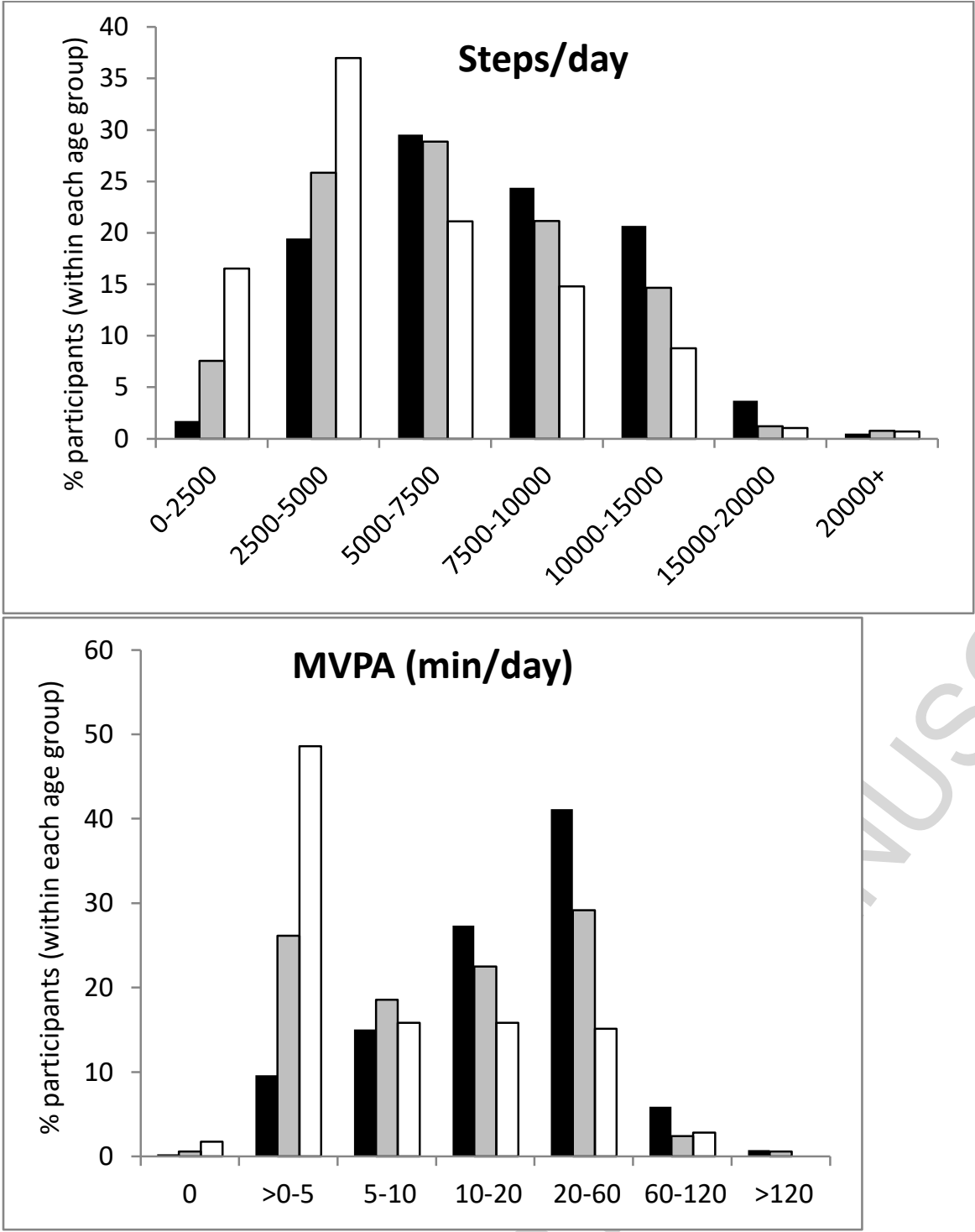


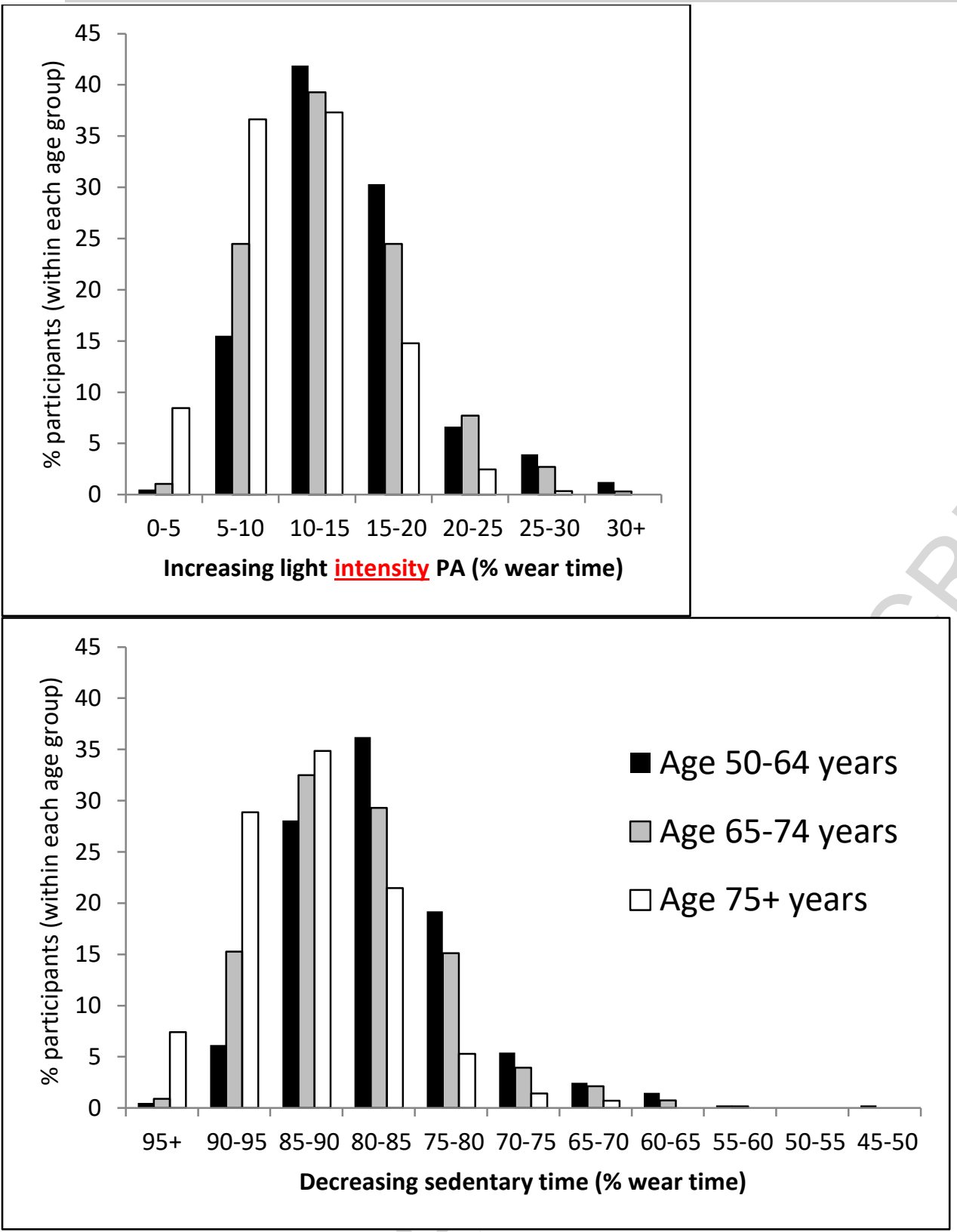

Abbreviation: Physical activity (PA); moderate-to-vigorous physical activity (MVPA); minutes (min)

Figure 2. Adjusted means of physical performance measures by categories of MVPA and age group 

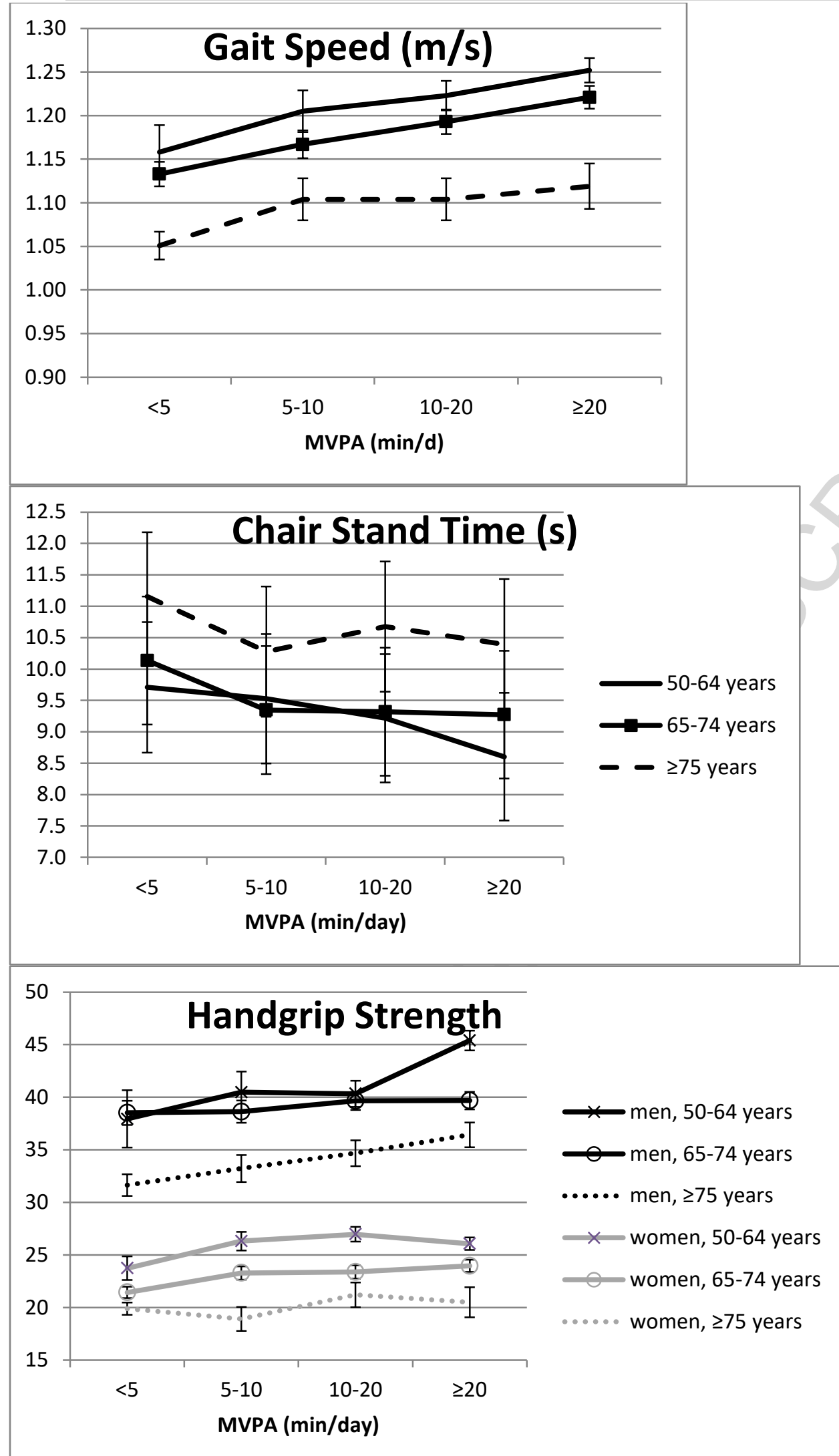

Abbreviations: moderate to vigorous physical activity (MVPA). Adjustment model: age, sex, cohort, wear time, season of physical activity monitor worn, residence in New England or other, body mass index, diabetes, cardiovascular disease, hypertension, current smoking, cancer, \%SED.

Table 2. Relations of MVPA to physical performance measures 


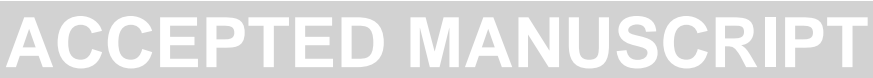

\begin{tabular}{|c|c|c|c|c|c|c|c|c|c|}
\hline \multirow{2}{*}{$\begin{array}{l}\text { Physical } \\
\text { Activity } \\
\text { Variable } \\
\end{array}$} & \multirow[b]{2}{*}{ Model } & \multicolumn{2}{|c|}{ Gait Speed $(\mathrm{m} / \mathrm{s})$} & \multicolumn{2}{|c|}{ In(Chair Stand) } & \multicolumn{2}{|c|}{$\begin{array}{l}\text { Handgrip Strength } \\
\text { (Men) }\end{array}$} & \multicolumn{2}{|c|}{$\begin{array}{l}\text { Handgrip Strength } \\
\text { (Women) }\end{array}$} \\
\hline & & B est. \pm SE & $p$ & B est. \pm SE & $p$ & B est. \pm SE & $p$ & B est. $\pm S E$ & $p$ \\
\hline Log MVPA & 1 & $\begin{array}{l}0.048 \pm \\
0.005\end{array}$ & $\begin{array}{c}<.000 \\
1 \\
\end{array}$ & $\begin{array}{c}-0.057 \pm \\
0.006 \\
\end{array}$ & $\begin{array}{c}<.000 \\
1\end{array}$ & $0.58 \pm 0.34$ & 0.090 & $0.64 \pm 0.19$ & 0.0008 \\
\hline & 2 & $\begin{array}{c}0.041 \pm \\
0.005\end{array}$ & $\begin{array}{c}<.000 \\
1\end{array}$ & $\begin{array}{c}-0.047 \pm \\
0.007\end{array}$ & $\begin{array}{c}<.000 \\
1\end{array}$ & $0.56 \pm 0.37$ & 0.125 & $0.81 \pm 0.20$ & $<.0001$ \\
\hline & $2+\operatorname{SED}(\%)$ & $\begin{array}{c}0.041 \pm \\
0.006\end{array}$ & $\begin{array}{c}<.000 \\
1\end{array}$ & $\begin{array}{c}-0.044 \pm \\
0.008\end{array}$ & $\begin{array}{c}<.000 \\
1\end{array}$ & $1.25 \pm 0.42$ & $\begin{array}{l}0.00 \\
3\end{array}$ & $1.03 \pm 0.26$ & $<.0001$ \\
\hline & INT $x$ age & & 0.783 & & 0.155 & & 0.866 & & 0.289 \\
\hline $\begin{array}{l}\text { MVPA }(<5 \\
\min \text { vs. } \geq 5 \\
\min / \text { day })\end{array}$ & $2+\operatorname{SED}(\%)$ & $\begin{array}{l}0.062 \pm \\
0.013\end{array}$ & $\begin{array}{c}<.000 \\
1\end{array}$ & $\begin{array}{c}-0.079 \pm \\
0.017\end{array}$ & $\begin{array}{c}<.000 \\
1\end{array}$ & $1.51 \pm 0.91$ & 0.098 & $2.05 \pm 0.50$ & $<.0001$ \\
\hline
\end{tabular}

Abbreviations: Moderate to vigorous physical activity (MVPA); sedentary time as a percent of wear time (SED [\%]); standard error (SE); interaction (INT).

The following variables were natural log transformed: chair stand time and MVPA. Beta estimate (B est.) is in units of physical performance variable per physical activity variable difference. For the outcomes gait speed and handgrip strength, higher is better. For chair stand time, lower is better.

Model 1: adjusted for age, sex, cohort, wear time, season of physical activity monitor worn, residence in New England or other

Model 2 (in addition to Model 1 adjustments): body mass index, diabetes, cardiovascular disease, hypertension, current smoking, cancer

Interaction significance was tested only for model 1 . Significant $p$-values were bolded for significance $(p<0.05$ for regression and $p<0.1$ for interaction analysis) 
Table 3. Relations of physical activity to physical performance, by age group

\begin{tabular}{|c|c|c|c|c|c|c|c|c|c|c|c|}
\hline \multirow[t]{2}{*}{$\begin{array}{l}\text { Phys. } \\
\text { Perf. }\end{array}$} & \multirow{2}{*}{$\begin{array}{l}\text { Physical } \\
\text { Activity } \\
\text { Variable }\end{array}$} & & \multicolumn{2}{|c|}{ Total sample } & \multirow{2}{*}{$\begin{array}{l}\text { P for } \\
\text { INT by } \\
\text { age }\end{array}$} & \multicolumn{2}{|c|}{$\begin{array}{c}\text { Age } 50-64 \\
(n=408)\end{array}$} & \multicolumn{2}{|c|}{$\begin{array}{c}\text { Age 65-74 } \\
(n=665)\end{array}$} & \multicolumn{2}{|c|}{$\begin{array}{l}\text { Age } \geq 75 \\
(n=287)\end{array}$} \\
\hline & & Model & B est. $\pm S E$ & $\mathrm{p}$ & & B est. $\pm S E$ & $\mathrm{p}$ & B est. $\pm S E$ & $\mathrm{p}$ & B est. $\pm S E$ & $\mathrm{p}$ \\
\hline \multirow{5}{*}{ 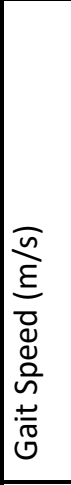 } & $\begin{array}{l}\text { Steps (1000 } \\
\text { steps) }\end{array}$ & 1 & $\begin{array}{l}0.006 \pm \\
0.001\end{array}$ & $\begin{array}{l}0.000 \\
1\end{array}$ & 0.032 & $\begin{array}{c}0.004 \pm \\
0.003\end{array}$ & 0.148 & $\begin{array}{c}0.004 \pm \\
0.002\end{array}$ & $\begin{array}{l}0.03 \\
7\end{array}$ & $\begin{array}{l}0.011 \pm \\
0.003\end{array}$ & $\begin{array}{l}0.000 \\
5\end{array}$ \\
\hline & & 2 & $\begin{array}{l}0.003 \pm \\
0.001\end{array}$ & 0.018 & -- & $\begin{array}{l}0.001 \pm \\
0.002\end{array}$ & 0.612 & $\begin{array}{c}0.002 \pm \\
0.002\end{array}$ & $\begin{array}{l}0.35 \\
9\end{array}$ & $\begin{array}{l}0.009 \pm \\
0.003\end{array}$ & 0.006 \\
\hline & SED & 1 & $\begin{array}{c}-0.005 \pm \\
0.001\end{array}$ & $\begin{array}{l}<.000 \\
1\end{array}$ & 0.027 & $\begin{array}{c}-0.003 \pm \\
0.001\end{array}$ & 0.031 & $\begin{array}{c}-0.004 \pm \\
0.001\end{array}$ & $\begin{array}{l}0.00 \\
2\end{array}$ & $\begin{array}{c}-0.008 \pm \\
0.002\end{array}$ & $\begin{array}{l}<.000 \\
1\end{array}$ \\
\hline & $\begin{array}{l}\text { (1\% or 10 } \\
\min )\end{array}$ & 2 & $\begin{array}{c}-0.004 \pm \\
0.001\end{array}$ & $\begin{array}{l}<.000 \\
1\end{array}$ & -- & $\begin{array}{c}-0.002 \pm \\
0.001\end{array}$ & 0.127 & $\begin{array}{c}-0.003 \pm \\
0.001\end{array}$ & $\begin{array}{l}0.02 \\
1\end{array}$ & $\begin{array}{c}-0.007 \pm \\
0.002\end{array}$ & $\begin{array}{l}0.000 \\
3\end{array}$ \\
\hline & & $\begin{array}{c}2+\mathrm{MVP} \\
\mathrm{A}\end{array}$ & $\begin{array}{c}0.0002 \pm \\
0.001\end{array}$ & 0.876 & -- & $\begin{array}{l}0.001 \pm \\
0.002\end{array}$ & 0.518 & $\begin{array}{c}0.001 \pm \\
0.001\end{array}$ & $\begin{array}{l}0.50 \\
5 \\
\end{array}$ & $\begin{array}{c}-0.002 \pm \\
0.002 \\
\end{array}$ & 0.327 \\
\hline \multirow{5}{*}{ 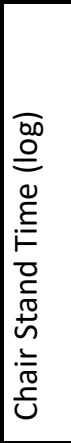 } & $\begin{array}{l}\text { Steps (1000 } \\
\text { steps) }\end{array}$ & 1 & $\begin{array}{c}-0.010 \pm \\
0.002\end{array}$ & $\begin{array}{l}<.000 \\
1\end{array}$ & 0.266 & -- & 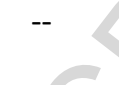 & & -- & -- & -- \\
\hline & & 2 & $\begin{array}{c}-0.007 \pm \\
0.002\end{array}$ & $\begin{array}{l}0.000 \\
2\end{array}$ & -- & -- & & -- & -- & -- & -- \\
\hline & SED & 1 & $\begin{array}{c}0.006 \pm \\
0.001\end{array}$ & $\begin{array}{l}<.000 \\
1\end{array}$ & 0.071 & $\begin{array}{l}0.005 \pm \\
0.002\end{array}$ & 0.011 & $\begin{array}{c}0.005 \pm \\
0.002\end{array}$ & $\begin{array}{l}0.00 \\
4\end{array}$ & $\begin{array}{c}0.010 \pm \\
0.003\end{array}$ & $\begin{array}{l}0.000 \\
4\end{array}$ \\
\hline & $\begin{array}{l}\text { (1\% or 10 } \\
\min )\end{array}$ & 2 & $\begin{array}{c}0.005 \pm \\
0.001\end{array}$ & $\begin{array}{l}<.000 \\
1\end{array}$ & -- & $\begin{array}{l}0.003 \pm \\
0.002\end{array}$ & 0.147 & $\begin{array}{c}0.004 \pm \\
0.002\end{array}$ & $\begin{array}{l}0.01 \\
3\end{array}$ & $\begin{array}{c}0.009 \pm \\
0.003\end{array}$ & 0.002 \\
\hline & & $\begin{array}{c}2+M V P \\
A\end{array}$ & $\begin{array}{c}0.001 \pm \\
0.001\end{array}$ & 0.596 & -- & $\begin{array}{c}-0.002 \pm \\
0.002\end{array}$ & 0.406 & $\begin{array}{c}0.0003 \pm \\
0.002\end{array}$ & $\begin{array}{l}0.86 \\
1\end{array}$ & $\begin{array}{c}0.005 \pm \\
0.004\end{array}$ & 0.221 \\
\hline \multirow{5}{*}{ 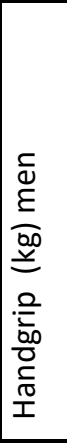 } & $\begin{array}{l}\text { Steps (1000 } \\
\text { steps) }\end{array}$ & 1 & $-0.16 \pm 0.09$ & 0.077 & 0.016 & $-0.54 \pm 0.19$ & 0.004 & $-0.07 \pm 0.13$ & $\begin{array}{l}0.57 \\
0\end{array}$ & $0.22 \pm 0.16$ & 0.163 \\
\hline & & 2 & $-0.19 \pm 0.09$ & 0.043 & & $-0.54 \pm 0.20$ & 0.007 & $-0.14 \pm 0.13$ & $\begin{array}{l}0.30 \\
2\end{array}$ & $0.20 \pm 0.16$ & 0.223 \\
\hline & SED & 1 & $0.09 \pm 0.05$ & & 0.034 & $0.27 \pm 0.10$ & 0.010 & $-0.01 \pm 0.07$ & $\begin{array}{l}0.84 \\
4\end{array}$ & $0.08 \pm 0.10$ & 0.444 \\
\hline & $\begin{array}{l}\text { (1\% or 10 } \\
\text { min) }\end{array}$ & 2 & $0.10 \pm 0.05$ & & -- & $0.26 \pm 0.11$ & 0.019 & $0.01 \pm 0.07$ & $\begin{array}{l}0.86 \\
1\end{array}$ & $0.11 \pm 0.11$ & 0.280 \\
\hline & & $\begin{array}{c}2+\mathrm{MVP} \\
\mathrm{A}\end{array}$ & $0.19 \pm 0.06$ & 0.001 & -- & $0.41 \pm 0.12$ & $\begin{array}{l}0.000 \\
8 \\
\end{array}$ & $0.04 \pm 0.09$ & $\begin{array}{l}0.67 \\
1 \\
\end{array}$ & $0.30 \pm 0.12$ & 0.013 \\
\hline \multirow{5}{*}{ 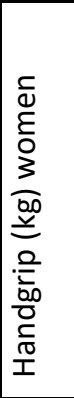 } & $\begin{array}{l}\text { Steps (1000 } \\
\text { steps) }\end{array}$ & 1 & $0.09 \pm 0.06$ & 0.125 & 0.711 & -- & -- & -- & -- & -- & -- \\
\hline & & 2 & $0.11 \pm 0.06$ & 0.078 & & -- & -- & -- & -- & -- & -- \\
\hline & SED & 1 & $-0.05 \pm 0.04$ & 0.133 & 0.025 & $-0.03 \pm 0.06$ & 0.682 & $\begin{array}{c}-0.001 \pm \\
0.05\end{array}$ & $\begin{array}{l}0.99 \\
2\end{array}$ & $-0.25 \pm 0.09$ & 0.004 \\
\hline & $\begin{array}{l}(1 \% \text { or } \sim 10 \\
\min )\end{array}$ & 2 & $-0.05 \pm 0.04$ & 0.147 & -- & $-0.01 \pm 0.06$ & 0.883 & $\begin{array}{l}0.02 \pm \\
0.05\end{array}$ & $\begin{array}{l}0.77 \\
5\end{array}$ & $-0.27 \pm 0.09$ & 0.003 \\
\hline & & $\begin{array}{c}2+\mathrm{MVP} \\
\mathrm{A}\end{array}$ & $0.06 \pm 0.05$ & 0.165 & -- & $0.06 \pm 0.08$ & 0.421 & $\begin{array}{l}0.01 \pm \\
0.07\end{array}$ & $\begin{array}{l}0.05 \\
3\end{array}$ & $-0.14 \pm 0.12$ & 0.233 \\
\hline
\end{tabular}

Abbreviations: Physical performance measure (Phys. Perf.); moderate to vigorous physical activity (MVPA); sedentary time as a percent of wear time (SED [\%]); standard error (SE); interaction (INT).

The following variables were log-transformed: chair stand time and MVPA. Beta estimate (B est.) is in units of physical performance variable per physical activity variable difference. For the outcomes gait speed and handgrip strength, higher is better. For chair stand time, lower is better.

Model 1: adjusted for age, sex, cohort, wear time, season of physical activity monitor worn, residence in New England or other

Model 2 (in addition to Model 1 adjustments): body mass index, diabetes, cardiovascular disease, hypertension, current smoking, cancer 
Interaction significance was tested only for model 1 . Significant $p$-values were bolded for significance $(p<0.05$ for regression and $p<0.1$ for interaction analysis) 